\title{
Gramsci, o "folclore" e o dia 22 de agosto: observações impertinentes
}

Andrea Ciacchi

Professor da Universidade Federal do Pará

\section{Resumo}

As "Observações sobre o Folclore" correspondem, como se sabe, à reunião de quatro textos curtos de Gramsci dedicados à reflexão acerca das manifestações e, sobretudo, da "concepção do mundo e da vida" do "povo" - ou seja, "das classes subalternas e instrumentais de toda forma de sociedade até agora existente". Nesta comunicação, busco contrapor as idéias gramscianas sobre cultura popular à concepção trivial de folclore no âmbito da escola brasileira, parcialmente fundamentada na obra de Câmara Cascudo.

Palavras-chave: Cultura Popular; Identidade Nacional; Câmara Cascudo.

\section{Résumé}

Les "Observations sur le Folklore" réunissent, comme chacun sait, quatre courts textes de Gramsci consacrés aux manifestations et, notamment, à la "conception du monde et de la vie" du "peuple", à savoir, "des classes subalternes et instrumentales de toute forme de société constituée jusqu'à présent". Dans mon rapport, je vais opposer les idées de Gramsci sur la culture populaire à l'idée du folklore présente dans l'école brésilienne qui s'est formée, en quelque mesure, à partir de l'oeuvre de Camara Cascudo.

Mots-clés: Culture Populaire; L'identité Nationale; Camara Cascudo. 
s "Observações sobre o Folclore" correspondem, como se sabe, à
reunião póstuma de quatro textos curtos de Gramsci dedicados à
reflexão acerca das manifestações e, sobretudo, da "concepção do mundo e da vida" do "povo" - ou seja, "das classes subalternas e instrumentais de toda forma de sociedade até agora existente". Antes disso, porém, é oportuno lembrar a posição que elas ocupam no campo italiano do debate cultural das primeiras décadas do século Vinte: elas, com efeito, constituem um dos primeiros e mais contundentes conjuntos de reflexões contra as concepções idílicas e "harmonistas" do folclore, que ainda exalavam do passado romântico e mesmo setecentista ${ }^{1}$.

O texto gramsciano é bem conhecido, mas convém relembrá-lo e contextualizá-lo, em síntese, para que a nossa argumentação possa fluir mais ligeiramente. Ele, aliás, sustenta-se em outras bem conhecidas concepções, como a da integral historicidade da cultura - e da cultura italiana, em particular -, e nas suas posições sobre intelectuais, "senso comum" e hegemonia. Mas, aqui, por enquanto, importa sublinhar o caráter "antiromântico" dessas concepções gramscianas. De fato, tanto na Itália fascista quanto no Brasil contemporâneo, os conceitos românticos, embora aparente e frequentemente questionados, continuam dominando sempre que se esquece o caráter dramático da existência dos desníveis culturais no interior das sociedades complexas. Para o romantismo, como veremos, só existia o "povo", entidade que representava e representa um valor ideológico específico: reconhecer-lhe os caracteres significa(va) uma operação de "resgate" de um absoluto abstrato subjacente às deformações introduzidas pela História (e pelas suas contradições). Para uma concepção historicista, ao contrário, os desníveis de cultura - ou seja, os determinantes dos fatos folclóricos - são o produto de um processo histórico caracterizado por

\footnotetext{
${ }^{1}$ Boa parte destas observações tem sua origem nas atividades do "Laboratório de Estudos da Oralidade", grupo de pesquisa multidisciplinar ativo na UFPB. Agradeço a colaboração de colegas e alunos que, desde 1994, me ajudaram nas considerações, em particular Maria Ignez e Marcos Ayala. Exigências de espaço impedem que inclua neste texto as minhas e nossas reflexões a partir da obra de Florestan Fernandes sobre folclore e educação (cf., sobretudo, FERNANDES, 1979).
} 
contrastes e confrontos culturais, e por divisões e fraturas, frequentemente dramáticas, entre classes dominantes e culturalmente hegemônicas e classes dominadas e culturalmente subalternas, porque excluídas da produção ou do gozo de determinados bens culturais. Quaisquer concepções que esqueçam a existência e a natureza desses contrastes, quaisquer concepções "harmonistas" do folclore, constituem, portanto, uma tentativa arbitrária e errônea de reintrodução de valores "absolutos" e a-históricos (Cf. CIRESE, 1997, p. 80 e passim).

É nessa perspectiva que as observações gramscianas se movem, aprofundando, porém, dialeticamente, os elementos da questão. Não só elas recusam o caráter "pitoresco" (GRAMSCI, 1968, p. 183) do folclore, e questionam o seu interesse para a "erudição" (Ibidem, p. 184), mas, sobretudo, afirmam que ele deve ser estudado como "concepção do mundo e da vida" (inclusive, portanto, na sua perspectiva de "cultura imaterial" - nós e o IPHAN diríamos hoje), “de determinados estratos (determinados no tempo e no espaço) da sociedade, em contraposição [...] com as concepções do mundo 'oficiais' (ou, em sentido mais amplo, das partes cultas das sociedades historicamente determinadas), que se sucederam no desenvolvimento histórico" (Ibidem).

Se essas passagens constituem a bem conhecida introdução conceitual à problemática mais ampla abordada por Gramsci nos seus Cadernos (ele também faz menção a elementos como religiosidade popular, "moral do povo", "direito natural”, cantos populares etc.), é necessário lembrar que a questão da presença do "folclore" na escola também interessa a Antonio Gramsci. Trata-se, aliás, de um elemento decisivo para que a nossa articulação com a realidade brasileira contemporânea se sustente mais solidamente. Para melhor introduzir esse aspecto, é oportuno não esquecer que, embora Gramsci afirme que "o folclore não deve ser concebido como algo bizarro, mas como algo muito sério e que deve ser levado a sério" (Ibidem, p. 186), a posição subalterna dos fatos folclóricos, função histórica da subalternidade das classes que do folclore são criadoras e portadoras, constitui um nó sobremaneira problemático: trata-se, com efeito, de uma 
concepção do mundo não somente não elaborada e assistemática, pois o povo (isto é, o conjunto das classes subalternas e instrumentais de toda forma de sociedade até agora existente) não pode - por definição - ter concepções elaboradas, sistemáticas e politicamente organizadas e centralizadas em seu (ainda que contraditório) desenvolvimento, como também múltipla; não apenas no sentido de diverso, de justaposto, mas no sentido de estratificado, indo do mais grosseiro ao menos grosseiro, se é que não se deve mesmo falar de um aglomerado indigesto de fragmentos de todas as concepções do mundo e da vida que se sucederam na história, sendo que tão-somente no folclore podem ser encontrados os documentos incompletos e contaminados que sobreviveram da maior parte dessas concepções (Ibidem, p. 184).

Assim, aparentemente, ao lado de uma evidente legitimação de um objeto (e de um objeto de estudo), surgiria uma drástica desqualificação das suas formas e do seu conteúdo. Melhor dizendo, ainda que "legítimos" (historicamente legítimos, aliás), esses conteúdos e essas formas (os fatos folclóricos, flagrados na sua historicidade de produtos de um processo estratificador) não possuem validade, por si só, na perspectiva de uma utilização político-cultural. Ainda que contraposto à cultura oficial e hegemônica, o folclore não tem (não pode ter, por sua subalternidade) os elementos e as "qualidades" necessárias para se tornar, ele mesmo, cultura hegemônica ${ }^{2}$.

A chave para desatar esta aparente contradição (mas se trata de uma contradição que só com alguma ingenuidade se enxergaria como tal) encontra-se, como não poderia deixar de ser, numa perspectiva ao mesmo tempo dialética e antropológica, na indissolubilidade entre fatos culturais (aí incluindo as "concepções do mundo e da vida") e grupos sociais. Essa "solidariedade" pertence à esfera histórica e sociológica, não se transmitindo direta ou automaticamente, em termos de "valores", à sua eventual viabilidade política ou educacional. É também verdade que nem tudo, no folclore, é “atraso": existem estratos

\footnotetext{
${ }^{2}$ Uma discussão completa - e definitiva, no meu entender - desta questão e dos seus corolários e consequiências, está em CIRESE (1976).
} 
fossilizados, que refletem condições de vida passada e que são, portanto, conservadores e reacionários; e os que são uma série de inovações, frequentemente criadoras e progressistas, espontaneamente determinadas por formas e condições de vida em processo de desenvolvimento e que estão em contradição (ou são apenas diferentes) com a moral dos estratos dirigentes (GRAMSCI, 1968, p. 185).

Assim, tudo, no folclore, é histórico: a própria dialética entre classes sociais, e a sua realização prática e real na arena da História. Mas, como transferir esse conjunto de questões para a esfera da escola? Gramsci, no texto que estamos utilizando, remete-se a um debate entre dois intelectuais italianos, o historiador Raffaele Ciampini (1895-1976) e Giovanni Crociani, então Diretor do Ensino Público de Bolonha. Eles parecem concordar quanto à utilidade de inserir o ensino do folclore nas "escolas em que são preparados os futuros professores", , no que são questionados por Gramsci, que lhes aponta contradições e inconsistências argumentativas. Mas a questão é complexa, pois os dois autores não podem possuir as mesmas concepções de Gramsci, que concebe a escola italiana como engendrada na esfera hegemônica, e sabe, por isso, que ela não pode admitir que o folclore (portador, como vimos, de inúmeros elementos "subalternos", mas também de numerosos conteúdos "concorrentes" ou mesmo "contrários") se transforme num conteúdo "positivo" do ensino público:

Esta atividade formadora própria do Estado, que se exprime - além de na atividade política - particularmente na escola, não se desenvolve sobre o nada e a partir do nada: na realidade, ela concorre e entra em contradição com outras concepções, explícitas e implícitas e, entre estas, o folclore não é das menores e menos tenazes; conseqüentemente, deve ser "superado". Conhecer o folclore significa, portanto, para o professor, conhecer quais são as outras concepções do mundo e da vida que trabalham de fato para a formação intelectual e moral das

3 A "Escola Normal", no modelo da sua homônima francesa, foi instituída no Reino de Sardenha, em 1859, antes mesmo da data oficial da independência e reunificação italianas (1861). Cf. GENOVESI (1998). 
gerações mais jovens ${ }^{4}$, a fim de extirpá-las e substituí-las por concepções consideradas superiores (GRAMSCI, 1968, p. 186; grifo meu).

Por isso, finalmente, a posição gramsciana, introduzida pela fórmula célebre e já lembrada ([o folclore é] "algo muito sério e que deve ser levado a sério"), aponta (mas não conclusivamente, pois o tema não é retomado explicitamente em outras partes dos Cadernos) para uma solução que prevê "o nascimento de uma nova cultura entre as grandes massas populares, isto é, desaparecerá a separação entre cultura moderna e cultura popular ou folclore" (Ibidem, p. 187).

É certo que essas posições de Gramsci, ainda que não especificamente aprofundadas, são incompreensíveis fora do contexto das suas demais concepções sobre a escola, a cultura (em sentido estrito e nos seus desdobramentos artísticos) e a posição e as tarefas dos intelectuais orgânicos na Itália. Valeria, se aqui houvesse tempo e espaço, articular essas observações sobre o folclore às argutas e mais conhecidas reflexões gramscianas sobre literatura nacional-popular (Ibidem, p. 61-138), e, sobretudo, sobre o "caráter não nacional-popular da literatura italiana" (Ibidem, p. 61-102), em que são retomados, em mais amplo fôlego comparativo, os temas da "popularidade" de determinados traços culturais.

Para encerrar esta parte da minha argumentação, é oportuno informar que na escola italiana contemporânea, a favor ou contra Gramsci já é difícil dizer, não há a menor menção ao "folclore", à "cultura popular", nem no âmbito de estudos, por exemplo, sobre "patrimônio"... 5

Como sabemos, é bem diferente, oposta, aliás, a situação do "ensino do folclore" na escola brasileira. Tão numerosas - e tão complexas, por isso, também, mas não somente por isso - são as iniciativas e as diretrizes que

\footnotetext{
${ }^{4}$ Algo, como se sabe, vivenciado profundamente pelo jovem Gramsci, nascido e criado no interior da "atrasada" Sardenha e educado na escola "italiana", entre 1898 e 1911.

5 Só muito recentemente (2009), mas em esfera e âmbito completamente diferentes (a polêmica partidária em volta do "federalismo" reivindicado por setores separatistas do norte da Itália, agitou-se a bandeira do ensino da "história local" e dos "dialetos" na escola italiana.
} 
inserem elementos "populares", "folclóricos", "tradicionais" (etc.), no dia-adia da sala de aula, que aqui vou me limitar a algumas considerações de ordem conceitual e - paradoxalmente - pontual. Refiro-me, especificamente, ao universo de atividades e conteúdos que se organizam em volta do "dia do folclore" (22 de agosto) ou mesmo a todo o "mês do folclore" - agosto, justamente.

Neles (o dia e o mês, mas, verdade seja dita, em alguns casos ao longo do ano todo), a presença do "folclore" assume as mais variadas formas, nos mais coloridos embrulhos. Mulas sem cabeça e Saci-Pererês, capoeira e Zumbi dos Palmares, cirandas e quadrilhas, Vitalinos e Virgulinos, pau-a-pique e paus-de-sebo, cordéis e cantorias, versos e trovas, cantos e contos populares - et caetera - compartilham todo o seu potencial lúdico com um poderoso cabedal ideológico, eclético e contraditório. A partir da virada do século XX para o XXI, aliás, o paradoxo ideológico parece particularmente intrigante, pois os Parâmetros Curriculares Nacionais encarregaram-se de sistematizar e contextualizar uma contradição insanável.

Com efeito, no volume Pluralidade Cultural, dos PCN's para o Ensino Fundamental, o termo folclore ocorre num único parágrafo, este:

\subsubsection{O ser humano como agente social e produtor de cultura}

Um conhecimento fundamental para a leitura da Pluralidade Cultural são as muitas linguagens que se apresentam como fator de identidade de grupos e indivíduos. Conhecer e respeitar diferentes linguagens é decisivo para que o trabalho com este tema possa desenvolver atitudes de diálogo e respeito para com culturas distintas daquela que a criança conhece, do grupo do qual participa.

Este bloco oferece oportunidades de transversalidade com Artes, quando por exemplo a criança poderá aprender sobre a cerâmica artesanal de certa população, ou músicas e danças de certos grupos étnicos, como formas de linguagem. É muito importante que, ao propor a atividade, o professor contextualize seu significado para o grupo étnico ou cultural de onde se originou a proposta, para que o assunto não seja tratado como folclore, mas como elemento cheio de importância para a estruturação 
e manifestação da vida simbólica daquele grupo. É importante também tratar das relações que se estabelecem entre o ser humano como produtor, e os produtos dessas diferentes linguagens. Por exemplo, como determinado utensílio ou objeto de grande valor cultural, de cunho sagrado, é guardado ou como se procede à sua limpeza e manutenção, quem é o encarregado; como o boiadeiro cuida da sela que usa em seu cavalo, ou do berrante que usa ao lidar com o gado (BRASIL, 1997, p. 50, grifo meu).

Em outras palavras, para os alunos do ensino fundamental preconizase uma representação "não folclórica" da sociedade brasileira - uma "transversalidade" horizontal, porém ocultadora da dimensão vertical, da dimensão dos desníveis sociais e culturais, da dimensão de classe, muito embora, entre os "Objetivos gerais de Pluralidade Cultural para o Ensino Fundamental", esteja explícito o repúdio "a toda discriminação baseada em diferenças de raça/etnia, classe social, crença religiosa, sexo e outras características individuais ou sociais" (Ibidem, p. 40). Se o tema da "pluralidade cultural", portanto, se enriquece a partir de uma perspectiva que revela a diversidade, é impossível não reconhecermos o encobrimento da perspectiva que revelaria a desigualdade. Para lograr esse objetivo finemente ideológico, parece suficiente eliminar o "folclore".

Mas, e o dia e o mês "do folclore”? Não parece haver vestígios deles, nos PCN's em vigor. Entretanto, não é necessária uma pesquisa muito aprofundada para toparmos com as inúmeras iniciativas que caracterizam ao menos um dia, quando não um mês inteiro, em todos os estabelecimentos de ensino fundamental do país, públicos e privados. Uma descrição viva está neste texto, de uma educadora pernambucana, publicado numa monografia editada pela Fundação Joaquim Nabuco de Recife:

Nos últimos dez anos, tenho analisado mais criteriosamente os livros didáticos destinados às primeiras séries do então $1^{\circ}$ grau, hoje de acordo com a Lei de Diretrizes e Bases (LDB) da Educação Nacional as quatro séries iniciais do Ensino Fundamental.

E, desde então, uma pergunta vem amadurecendo: por que os autores dos livros didáticos não usam, com mais frequência, cumplicidade até, o folclore em suas obras? O fato folclórico, vivenciado no cotidiano escolar, traz, para 
a sala-de-aula, o lúdico, o prazeroso. Resgata experiências. Socializa conhecimentos. Estreitam relações pessoais e de grupos.

As escolas públicas e particulares trabalham intensamente, no mês de agosto, as diferentes manifestações folclóricas, aproveitando a deixa da data universal do folclore - 22/8. E, apesar de ser um mês longo - 23 dias úteis - transcorre gostosamente motivado pela riqueza, variedade e beleza de temas folclóricos. Ditados populares são analisados. Lendas e mitos são personificados. Brincadeiras e cantigas de roda são revividas nos recreios. Concursos de brincadeiras e brinquedos populares são realizados. Aulas de medicina popular com exposição de ervas e até o fabrico de chás e lambedores acontecem nas escolas. Receitas de pratos e bebidas típicas são trocadas. Danças e folguedos são vivenciados. Enfim, é um mês com alguma coisa diferente no ar, um diferencial significativo que o torna ímpar em relação aos demais meses do ano letivo, quase sempre tão cheios de mesmice... [...] (LINHARES, 1999).

A autora, a seguir, procede a uma crítica da abordagem que o folclore recebe nos livros didáticos e aponta como uma solução possível: “observar que o folclore permite uma aplicação concreta dos Parâmetros Curriculares Nacionais (PCNs) ao ser inserido nos conteúdos da "pluralidade cultural", um dos componentes dos temas transversais da atual política educacional no país" (Ibidem), o que, evidentemente, vai, ao mesmo tempo, ao encontro de e de encontro ao que observamos. A professora Thelma Regina Siqueira Linhares é aqui tomada como "tipo ideal” de uma legião de apaixonados brasileiros pelo "folclore", protagonistas, há décadas, desse movimento que, pelo menos a partir da instituição oficial do "dia do folclore" (1965), pretende restituir-lhe o seu caráter romântico e "harmonista". Mas onde está a raiz" desse movimento e, claro, dessa abordagem ideológica?

Não me parece possível avançar no caminho do desmascaramento anti-ideológico sem definir os pressupostos e os antecedentes de tão arraigados convencimentos nacionais. Refiro-me, aqui, ao pensamento de um intelectual de extraordinário alcance e efeito no senso comum relativo à cultura "popular", sobretudo na região Nordeste: Luís da Câmara Cascudo. 
A repercussão das suas idéias, em âmbitos acadêmicos e extra-acadêmicos é tão ampla que é possível afirmar que se trata de uma das fontes mais relevantes dos discursos contemporâneos sobre "identidade cultural" e “diversidade cultural". A ênfase, que agora recai mais acentuadamente nos fatos da cultura popular e do "folclore", servirá para uma melhor contextualização da discussão conceitual que se encontra antes e depois desse amplo parêntese.

De fato, um texto clássico e nunca suficientemente conhecido, como Literatura oral no Brasil, talvez o mais metodologicamente rigoroso na obra do erudito potiguar, está sempre despertando novas leituras, solicitando renovadas abordagens críticas, entre os pesquisadores que se dedicam ao horizonte delicado da cultura popular brasileira. Aqui, muito sucintamente, e sem nenhuma pretensão de alcançar rigor analítico ou de esgotar o conjunto das questões levantadas pelo texto, desejo apenas resenhar alguns marcos que definem opções e visões do autor, extraindo-os das páginas que constituem o primeiro capítulo do livro, o mais teórico e conceitual.

É evidente que as idéias centrais desenvolvidas no primeiro capítulo de Literatura oral no Brasil se aglutinam em volta das suas perspectivas teóricas e metodológicas, todas elas inspiradas pelas noções de "sobrevivência", “anonimato", tradição "estagnada", comparativismo. Nas páginas que pretendo discutir, adquirem ênfase expressões como "temas remotos" (CASCUDO, 1978, p. 22), “antiguidade", "persistência" e "anonimato" (Ibidem, p. 23), “indecisão cronológica” (Ibidem), “memória coletiva, indistinta" e "sobrevivência" (Ibidem), "cultura que [...] bebeu no leite da antiquidade" (Ibidem, p. 25), "menestréis da idade média" e “conservação ciumenta" (Ibidem, p. 26), etc. Resumindo como resumiram Marcos Ayala e Maria Ignez N. Ayala (1986, p. 15), “em outros termos, um conjunto de resíduos, de fragmentos de costumes e práticas culturais desaparecidas. Assim, torna-se difícil estabelecer os vínculos entre as manifestações populares e os contextos em que surgiram".

Ora, em 1952, quando Literatura Oral foi publicado pela primeira vez, a penetração da dialética nos estudos sociais, por um lado, e o interesse 
da sociologia em explorar as manifestações da cultura popular eram fatos ainda raros no Brasil. Assim, não se trataria aqui de exigir de Câmara Cascudo um posicionamento mais "problematizador", mais alinhado com o que hoje consideramos a justa contextualização dos fatos folclóricos. Antes, parece mais útil esboçar algumas reflexões que poderiam ter alguma utilidade para os nossos objetivos.

Em primeiro lugar, como é óbvio, o que está ausente desse capítulo, desse livro, de boa parte da obra de Câmara Cascudo e, enfim, ausente de toda essa orientação teórico-metodológica que, no Brasil, nos acostumamos a chamar de "folclorismo", é exatamente o Brasil das relações de trabalho, ou seja, o Brasil das classes sociais. Em nenhum trecho deste texto, pareceme, atenta-se para a correspondência (a "solidariedade sócio-cultural", diria o antropólogo italiano Alberto Mario Cirese [1979, passim]) entre diferentes manifestações culturais e diferentes estratos sociais. Tão-somente, quando frisa a "diferença", o autor encaminha a discussão para uma oposição “virtual" (pois não explicitada), entre "antigo" e "moderno", entre "ágrafo" e "erudito", entre algo que não consegue definir e a cultura "oficial". Por trás de cada manifestação mencionada por Câmara Cascudo, não se enxerga ninguém: nem mulheres nem homens reais. Ao contrário, quando o autor se empenha em descrever as várias disciplinas da cultura não popular (como faz no primeiro parágrafo da página 25), estamos diante de uma galeria de "arqueólogos", “sociólogos", “antropólogos", “eruditos da novelística", "músicos", "médicos", etc. Em outras palavras, a cultura popular parece "fazer-se por si mesma”, emergindo dessa zona indistinta e dotada de vitalidade própria que é o passado. Já a cultura "oficial", esta, é feita por homens vivos, atuantes, protagonistas da sociedade "real" e "moderna". Num parágrafo revelador das dificuldades acarretadas por essa orientação, Câmara Cascudo deixa entrever a distância que corre entre esferas culturais que, na realidade, estão distantes, antes, no plano histórico-social: “Ninguém deduzirá como o povo conhece a sua literatura e defende as características imutáveis dos seus gêneros. É como um estranho e misterioso cânon para cujo conhecimento não fomos iniciados" (CASCUDO, 1978, p. 26, grifos 
meus). Essa iniciação será porventura ligada ao conhecimento dos processos “específicos de criação” de que, alguns anos antes, já havia falado Amadeu Amaral (em Tradições populares)? Em caso afirmativo, teríamos, à revelia do próprio autor, a revelação de uma "incomunicabilidade" cultural derivada, antes, de uma distância social e econômica. Mas, não se poderia esperar de Câmara Cascudo (e de poucos, aliás, no Brasil provinciano daqueles anos 50) que se atentasse para as relações imediatas e necessárias entre "produção e reprodução da vida material" e a "vida espiritual", para usarmos o dicionário dos dialéticos.

Paradoxalmente, porém, o texto de Câmara Cascudo contém, também meio à revelia, uma trilha áspera que poderia levar o autor fora do terreno movediço em que se meteu. Ao citar com ênfase o folclorista e antropólogo francês Pierre Santyves, ele acaba, num primeiro momento (Ibidem, p. 24), aceitando uma espécie de declaração de cidadania para a consideração das "condições materiais" no estudo da cultura popular. Cito, traduzindo-o, um trecho do Manuel de Folklore (1933) de Santyves transcrito pelo próprio Câmara Cascudo: "Querer reservar o nome de folclore para cultura espiritual e opô-la à etnografia tomada no seu sentido de cultura material equivale a querer romper uma unidade realmente orgânica". As manifestações da literatura oral, parece dizer-nos Santyves (mas não a Câmara Cascudo), não são separadas da vida material de quem as pratica. Mais contundente parece-me o trecho do Manuel citado à pág. 30. Diz Santyves: "O folclore estuda a vida popular, mas no interior da vida civilizada. Não há matéria folclórica junto às populações nas quais não se pode distinguir entre duas culturas, a da classe instruída e a da classe popular" (grifo meu). O contexto de Santyves ainda está ligado a uma idéia de popular como antigo, atrasado, "não-civilizado", porém a vinculação entre cultura popular e estratificação social é clara, e provavelmente incompreendida e incompreensível para Câmara Cascudo. Valeria lembrar, nessa perspectiva, que o próprio Manual de folclore de Santyves (aqui citado e traduzido por Giuseppe Cocchiara em sua Storia del Folklore in Europa [1972, p. 532, grifo do autor francês]) afirma em outro lugar: 
A tradição popular não se pode comparar a um tesouro enterrado: é um fluxo de riquezas de toda ordem, uma transmissão sem fim de milhares e milhares de invenções humanas de que o povo se beneficia nas nações civilizadas. A corrente de ouro da tradição não repousa imóvel num escrínio lacrado, mas realiza, assim como os astros, o milagre do movimento perpétuo.

De forma algo astronômica..., o autor parece aqui reconhecer a cultura popular como fruto de um processo "real" de mudanças, transformações, não apenas uma "sobrevivência" do passado. Não se trata, evidentemente, de transformar Santyves num "campeão" da demologia moderna, mas acho interessante mostrar que haveria algo de mais desenvolvido na visão desse que foi uma das fontes de inspiração para a perspectiva teórico-metodológica de Câmara Cascudo.

A segunda observação que me parece cabível também aponta para um aparente paradoxo. Nisso também, Câmara Cascudo é "companheiro de viagem" de outros folcloristas brasileiros, tanto os que o influenciaram como os que ele próprio influenciará - mas também de estudiosos europeus da segunda metade do século XIX. No afã de demonstrar o caráter de sobrevivência da cultura popular, produzida, como ela seria, por sobras de fatos culturais do passado erudito (e que o pesquisador contemporâneo tem por tarefa reconstruir, nas suas etapas, através, quiçá, daquela famosa "imaginação adivinhadora"), acaba-se (sem querer, talvez, em muitos casos) por negar capacidade criadora e autonomia estética (se não, mais amplamente, cultural) às classes populares. É necessário insistir no desmascaramento desse paradoxo (na realidade um traço ideológico claríssimo), justamente porque o raciocínio (como qualquer construção ideológica - uma ilusão bem fundada nas aparências) é muito perigoso. Onde aparentemente enaltece (a "nobre" "origem" do folclore brasileiro...!), na realidade avilta ("o povo não sabe criar, quando muito re-cria"...). Encontro uma definição arguta desse impasse numa página de Cirese (1978: 160-161):

A esse trabalho de investigação histórica, sem dúvida profícuo [o autor refere-se às pesquisas italianas sobre a "poesia popular antiga" empreendidas por volta de 
1870], acompanha-se entretanto uma postura ideológica muito evidente: exalta-se a "beleza" da poesia popular "antiga", e recusa-se, por outro lado, a tradição oral contemporânea, apreciada somente se corresponde aos modelos antigos. Chega-se a declarar explicitamente (como o fez [o poeta italiano pós-romântico] Carducci) que o "povo moderno" não canta, e quando canta, canta bobagens. [...]. O mito romântico do "povo criador" entrava assim em contradição consigo mesmo: como é possível que esse idolatrado "povo" foi criador no passado e deixou de sê-lo no presente? À origem dessa postura está sem dúvida a crise social que se anunciava na Itália de então [e que, assumimos, não era tão diferente do Brasil dessa mesma época e das décadas sucessivas]. O "povo" contemporâneo começa a amedrontar, e por isso parece bom intentar essa fuga para o passado: identifica-se o "povo" do passado com a burguesia nascente, recusando a possibilidade de reconhecê-lo nas classes agrárias modernas.

Assim, povo "bonito" é povo do passado, possivelmente morto e enterrado. Povo bom é esse que só faz repetir o passado, o bom e velho passado em que a ordem social não esteve em discussão. À raiz desse equívoco, parece-me, está também a dificuldade (que se mantém até hoje), demonstrada por muitos folcloristas, em "ver" a cultura popular nas cidades, nas áreas urbanas, nas fábricas, etc. ${ }^{6}$. Numa palavra: ver-gramscianamente - a diversidade cultural como um continuиm da diversidade social, da sua diferença - da estratificação social, e, ao mesmo tempo, de enxergá-la também como conseqüência e "resíduo" da modernidade.

Não deve ter sido esse, provavelmente, o intuito consciente de Câmara Cascudo, embora não seja difícil relacionar esse perigo ideológico com a situação de proximidade da sua figura com o conjunto (ideológico, cultural, político) paternalista e conservador da elite nordestina em tempos de crise da economia açucareira. Vale, porém, ressaltar de novo que o impasse é particularmente ardiloso, pois, numa visão oriunda de uma espécie de ancien régime colonial, antigüidade é sintoma de nobreza, sinal de reconhecimento, patente de bons antecedentes culturais. O repentista é "herdeiro" de algum poeta grego ou menestrel medieval... A Grécia clássica

6. Veja a esse propósito: AYALA (1997). 
e a Idade Média cristã perfazem outras tantas lacunas lamentáveis no passado de um país que se olha para trás só vê índio selvagem. Deve ter sido bom "resgatar" esses momentos altos da história ocidental, nem que fosse através de gente "rude", "simples", milagrosamente imbuída do espírito dos grandes artistas do passado europeu. A literatura oral brasileira, assim, parece "psico-grafada", ou melhor, "árqueo-grafada": veio diretamente do passado, pulando as etapas da contextualização histórica e sociológica. Mais uma vez, ao que me parece, idéias (literalmente) fora do lugar.

Acresce-se, assim, mais um impasse. Além da contradição do mito romântico do povo criador e poeta, anuncia-se outra: a contradição dos vínculos entre folclore e identidade nacional. Como é possível que a cultura popular (brasileira) seja erguida, simultaneamente, a resumo, síntese, símbolo e summa da verdadeira cultura nacional, "marco identitário" de um país que se compraz em não enxergar os seus conflitos, se ela é feita de matéria histórica e geograficamente alheia? O brasileiro "se pertence" ou é de outrem? A contradição (que mereceria, evidentemente, uma formulação mais clara e ampla) atinge, sobretudo, esse "nacionalismo ibéricopopularesco" de um Ariano Suassuna (agora sim, fonte de uma pletora de discursos acerca da identidade que transitam com desenvoltura nos espaços das políticas públicas de cultura, educacionais do senso comum e dos debates jornalísticos), mas é fruto também de uma longa tradição de posicionamentos teóricos e metodológicos que não puderam (em alguns casos não quiseram) dar conta da complexidade real, essa que só se destrinça recorrendo à dialética. Afinal, a identidade brasileira (ou a sua diversidade cultural: agora não faz mais diferenças) é um “epítome vivo" do país (para parafrasear Euclides da Cunha), ou, antes, mera cópia de modelos ao mesmo tempo antigos e estrangeiros? Ainda com o empréstimo de uma reflexão de Roberto Schwarz ("Nacional por subtração" - texto famoso onde essas questões são bem mais profundamente expostas e discutidas, embora em outro âmbito), esse folclore (ou essa identidade/diversidade) é "postiço, inautêntico $[e]$ imitado", ou orgulho nacional de um país sem classes, sem história e sem contextos? 
Dessa forma, o tipo "ideal” da professora Thelma Regina e a figura "histórica" de Câmara Cascudo, solidariamente, encarregam-se de produzir um triplo efeito (triplo e, portanto, paradoxal): "limpar" o passado do folclore brasileiro, expurgando-o de toda e qualquer marca de classe (isto é, de qualquer marca histórica); torná-lo “estranho" e estrangeiro a si mesmo, numa variante recalcada de exotismo pitoresco; e, assim, finalmente, transformá-lo em algo incompreensível mas obrigatório - assim cumprindo a sua suprema tarefa ideológica.

Deve ser algo dessa natureza que esteve na base da "recusa" do PCN da Pluralidade Cultural, que, como vimos, recomenda "que o assunto não seja tratado como folclore" (BRASIL, 1997, p. 50). Mas é também, esse do PCN, um desejo não realizado, uma diretriz não cumprida, pelo menos nos dias de agosto.

Não cabe aqui - nem me caberia, em absoluto - aventar sugestões que busquem escapulir dos impasses que me parecem firmemente estabelecidos. Mas, talvez, uma releitura atenta das observações gramscianas sobre o folclore induzisse, se não a uma reformulação dos PCN's e/ou das práticas escolares agosteiras, a um reaparelhamento teóricometodológico das discussões sobre esse conjunto de temas e questões.

\section{Referências bibliográficas}

AYALA, Maria Ignez Novais. Por uma abordagem crítica do popular. Graphos; Revista da Pós-Graduação em Letras da UFPB. Vol. II; Número 4, João Pessoa, 1997. p. 36-45.

AYALA, Maria Ignez Novais; AYALA, Marcos. Cultura popular no Brasil. São Paulo: Ática. 1986.

BRASIL. Parâmetros Curriculares Nacionais. Vol. 10. Pluralidade Cultural. Orientação Sexual. Brasília: MEC/SEF. 1997.

CASCUDO, Luís da Câmara. Literatura Oral no Brasil. $2^{a}$ ed., Rio de Janeiro, José Olympio. 1978.

CIRESE, Alberto Mario. Intellettuali, folclore, istinto di classe. Note su Verga, Deledda, Scotellaro e Gramsci. Torino: Einaudi. 1976. 
CIRESE, Alberto Mario. Cultura egemonica e culture subalterne. Palermo: Palumbo.

CIRESE, Alberto Mario. Dislivelli di cultura e altri discorsi inattuali. Roma: Meltemi. 1997.

COCCHIARA, Giuseppe. Storia del Folklore in Europa. $4^{\mathrm{a}}$ ed., Torino: Boringhieri. 1972.

FERNANDES, Florestan. O folclore em questão, $2^{\mathrm{a}}$ ed., São Paulo: Hucitec. 1979.

GENOVESI, Giovanni. Storia della scuola in Italia dal Settecento ad oggi. $5^{\mathrm{a}}$ ed. Roma-Bari: Laterza. 1998.

GRAMSCI, Antonio. Literatura e vida nacional. Rio de Janeiro: Civilização Brasileira. 1968.

LINHARES, Thelma Regina Siqueira. Folclore e livro didático. Recife: Fundação Joaquim Nabuco. Parcialmente disponível em: http://www.educacaopublica.rj.gov.br/cultura/folclore/0001.html. Acesso em 20 de setembro de 2009. 1999.

SCHWARZ, Roberto. Que horas são? Ensaios. São Paulo: Companhia das Letras, 1987. 